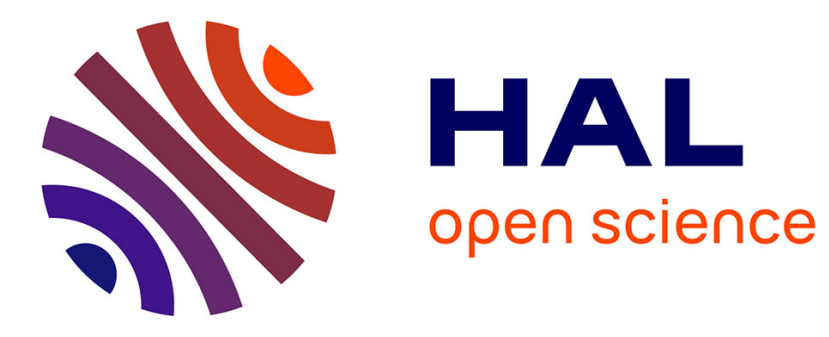

\title{
Optimal centralized control application on microgrids
}

Khaled Hajar, Ahmad Hably, Seddik Bacha, Ahmad Rafhi, Ziad Obeid

\section{To cite this version:}

Khaled Hajar, Ahmad Hably, Seddik Bacha, Ahmad Rafhi, Ziad Obeid. Optimal centralized control application on microgrids. REDEC 2016 - International Conference on Renewable Energies for Developing countries (REDEC 2016), Jul 2016, Beyrouth, Lebanon. 10.1109/REDEC.2016.7577549 . hal-01323250

\section{HAL Id: hal-01323250 \\ https://hal.science/hal-01323250}

Submitted on 30 May 2016

HAL is a multi-disciplinary open access archive for the deposit and dissemination of scientific research documents, whether they are published or not. The documents may come from teaching and research institutions in France or abroad, or from public or private research centers.
L'archive ouverte pluridisciplinaire HAL, est destinée au dépôt et à la diffusion de documents scientifiques de niveau recherche, publiés ou non, émanant des établissements d'enseignement et de recherche français ou étrangers, des laboratoires publics ou privés. 


\title{
Optimal centralized control application on microgrids
}

\author{
Khaled Hajar ${ }^{*+}$, Ahmad Hably ${ }^{*}$, Seddik Bacha *, Ahmad Rafhi ${ }^{\diamond}$, Ziad Obeid ${ }^{\diamond}$ \\ *Univ. Grenoble Alpes, GIPSA-Lab \\ F-38000 Grenoble, France. \\ khaled.hajar@gipsa-lab.grenoble-inp.fr \\ $\diamond$ Universite de Technologie et de Sciences Appliquees Libano-Francaise - Lebanon.
}

\begin{abstract}
In this paper, an optimization algorithm has been applied on a group of interconnected microgrids with the main grid. The objective is to maximize the benefits for all the elements of the grid. Results have shown the performance of the proposed algorithm.
\end{abstract}

\section{INTRODUCTION}

A microgrid (MG) is a smart small-scale power supply network that is designed to provide power for a small community enabling local power generation for local loads. It contains various small power generating sources which can be renewable energy sources (RES) and distributed generation (DG), that make it highly flexible and efficient, with energy storage systems (ESS) like batteries, hydraulic storage, electrical vehicles, etc. The size of a MG may range from housing estate to municipal regions.

Micro grid applications have different objectives and characteristics but they share some common technical problems due to the use of RES. Theses RES have an intermittent, random, non programmable nature, which makes it difficult to provide a continuous power supply to isolated loads and to assure energy dispatch of RES in distribution grids.

MG operates in a connected manner, but also in an isolated one in case of faults or maintenance [1]. However, it is also expected to provide sufficient generation capacity, controls and operational strategies to supply at least a portion of the load, after being disconnected from the distribution system and remains operational as an autonomous (islanded) entity [2].

Implementation of MG provides many advantages both for the user and for the distribution system operators (DSO). For the user's application, and when the MG is connected to the grid, it can improve network quality, reduce emissions and reduce the cost to be incurred. For the DSO, implementation of MGs and their distributed generation systems can reduce the power flow on transmission and distribution lines, so losses are reduced as well as costs for additional power [3]. In addition, the extra power produced by the MG can be sold to the DSO and vice-versa, which is considered as a benefit for both parties.

The research field of control and optimization a network of MGs has recently received much attention. A decentralized optimal state feedback of multi-power system has been proposed in [4]. In [5], a distributed Model Predective Control (MPC) has been proposed where controllers are supposed to operate separately, their design is based on a global model of the overall system. In [6], a decentralized linear quadratic Gaussian control (LQG) approach has been investigated. In [7], a mixed integer linear approach on modeling and optimization of microgrids has been proposed. In [8], the proposed controller optimizes the operation of the MG during interconnected operation. In [9], a model predictive control (MPC) for the optimal power exchanges in a network of microgrids (MGs) has been presented.

In this present paper, we apply a centralized control of the power flow among a network of MGs and with DSO inspired from [9]. This solution takes into account the economic profit of all the actors of the Grid (DSO and all the MGs). The paper is organized as follows. In Section II, MG elements are presented. MG modeling as well as optimization problem are developed in Section III. The results of the application of the methodology are presented and commented in Section IV. Section V provides some conclusions and perspectives.

\section{MICROGRID ELEMENTS}

In the literature, several models for $\mathrm{MG}$ have been proposed. We have inspired a model of $\mathrm{MG}$ from the 
modeling procedure proposed by [10]. Each MG integrates several units: local loads, wind power, photovoltaic (PV), distributed generation, and energy storage systems (ESS). Wind power and PV are affected by the variation of wind speed and solar irradiance respectively. ESS has two status: charging and discharging, depending on the loads and the production. A control unit (CU) is used in order to assure the local consumption, to maximize the power stored in ESS according to the approach proposed in our previous work [11]. The CU optimizes the control of each MG and reveals its state to a Global Management Controller (GMC). It shows if the

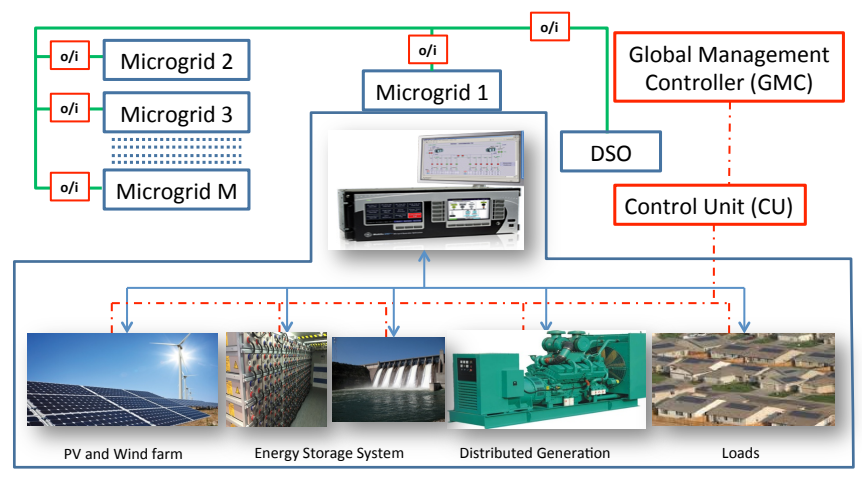

Fig. 1: Microgird composition.

MG has excess of power or vise versa. For each MG the goal can be achieved by controlling the charge/discharge of ESS, starting or stopping DG, and receiving/sending power from/to neighboring MGs. The GMC is dedicated to manage the power in the grid, the relation between MGs as well as with the DSO with a predicted control. It takes also the decision wherever the excess power is to be sent to other MGs or to DSO. The different elements of MG are presented in Fig.1. This figure also shows us the units of producing or consuming energy. Also a microgrid can be connected or disconnect from DSO or/and can be connected to other MGs.

To summarize, a MG integrates:

- ESS improving the quality, and reliability of supply.

- Loads representing consumers demand.

- Control Unit (CU) transferring the data to GMC.

- RES providing clean sources.

- DG improving the reliability of supply.

- DSO providing/purchasing power for/from the MG.

III. MICROGRID MODELING AND OPTIMIZATION

\section{A. Modeling}

Figure 2 shows the interaction among MGs on one hand and between DSO and MGs on the other hand.
The power flow is as the following:

- $P_{S, D}$ : Power sold by the DSO $(\mathrm{kW})$.

- $P_{S, M}$ : Power sold by the MG $(\mathrm{kW})$.

- $P_{B, D}$ : Power bought by the DSO $(\mathrm{kW})$.

- $P_{B, M}$ : Power bought by the MG $(\mathrm{kW})$.

- $P_{b a l}$ : Power balance.

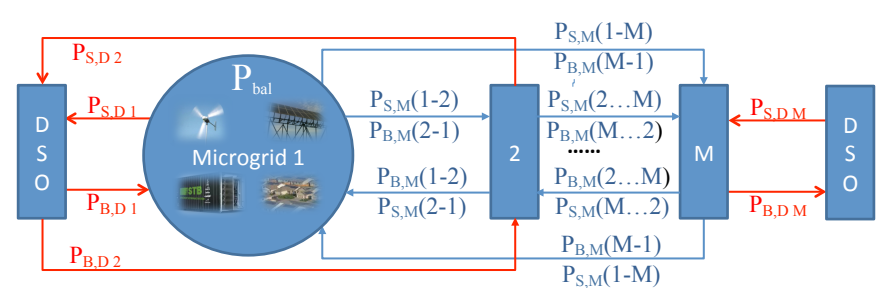

Fig. 2: Power flow in the grid (MG+DSO).

The stored energy equation in each MG:

$$
\begin{aligned}
x(i, t+k)= & x(i, t+k-1)+ \\
& \delta_{\text {char }, i} P_{\text {char }}(i, t+k)-\delta_{\text {dis }, i} P_{\text {dis }}(i, t+k)
\end{aligned}
$$

where

- $x$ : Stored energy $(\mathrm{kWh})$

- $\delta_{\text {char }, i}$ : Charging efficiency of the ESS in the i-th MG.

- $\delta_{d i s, i}$ : Discharging efficiency of the ESS in the i-th MG.

- $P_{\text {cha }}$ : Charged energy $(\mathrm{kWh})$.

- $P_{\text {dis }}$ : Discharged energy $(\mathrm{kWh})$.

\section{B. Optimization Formulation}

A nonlinear centralized optimization is used to formulate the energy management in MG [8]. Our objective is to optimize the grid in way that the power generation, power balance, ESS, energy exchange between MGs are satisfied under certain constraints that will be presented later. The cost function $C_{f}$ to be maximized is given by the following equation:

$$
\begin{aligned}
& C_{f}=\sum_{k=1}^{N_{c}} \sum_{i=1}^{m}\left[\mu_{D}(k) P_{S, D}(i, t+k) T_{S, D}(i, t+k)\right. \\
& \left.-\hat{\mu}_{D}(k) P_{B, D}(i, t+k) T_{B, D}(i, t+k)\right] \\
& +\sum_{k=1}^{N_{c}} \sum_{i=1}^{M} \sum_{j, j \neq i}^{m}\left[\mu_{M}(k) P_{S, M}(i, j, t+k) T_{S, M}(j, t+k)\right. \\
& \left.-\hat{\mu}_{M}(k) P_{B, M}(i, j, t+k) T_{B, M}(j, t+k)\right]
\end{aligned}
$$

with

- $k$ : Prediction step.

- $t$ : Control step.

- $N_{c}$ : Control horizon. 
- $i, j:$ MG index.

- $m$ : MGs number.

- $\mu_{D}(k)$ : Scale factor depending on the benefit of selling power to DSO.

- $\mu_{M}(k)$ : Scale factor depending on the benefit of selling power to the MGs.

- $\hat{\mu}_{D}(k)$ : Scale factor depending on the benefit of buying power from DSO.

- $\hat{\mu}_{M}(k)$ : Scale factor depending on the benefit of buying power from the MGs.

- $T_{S, D}$ : Expected cost value of selling energy by the DSO (€/kWh).

- $T_{S, M}$ : Expected cost value of selling energy by the MG (€/kWh).

- $T_{B, D}$ : Expected cost value of buying energy by the DSO (€/kWh).

- $T_{B, M}$ : Expected cost value of buying energy by the $\mathrm{MG}(€ / \mathrm{kWh})$.

As described in Fig. 2, the first term in the objective function is related to the energy sold/bought to/from DSO and the second term is related to the energy sold/bought to/from neighboring MGs. The constraints for this optimization problem are given in the following section.

\section{Constraints}

A MG cannot buy and sell energy at the same time. Selling can be done when the MG has an excess of power otherwise MG can buy power when its production is lower than its consumption:

- If $\Delta P_{M G, j}(t+k)<0$ then $P_{S, D}(i, t+k)=0$ and $P_{S, M}(j, i, t+k)=0$

- If $\Delta P_{M G, j}(t+k)>0$ then $P_{B, D}(i, t+k)=0$ and $P_{B, M}(j, i, t+k)=0$

with $\Delta P_{M G, j}(t+k)=\sum\left(P_{E P, j}(t+k)-P_{E L, j}(t+k)\right)$, Where

- $\Delta P_{M G, j}$ : Power balance of $\mathrm{j}$-th MG at $(\mathrm{t}+\mathrm{k})$ instant.

- $P_{E P, j}$ : Power of the expected production of $\mathrm{j}$-th $\mathrm{MG}$ at $(t+k)$ instant.

- $P_{E L, j}$ : Power of the expected load of $\mathrm{j}$-th $\mathrm{MG}$ at $(t+k)$ instant.

An upper and a lower bound $\left(P_{S, D, \min }, P_{S, D, \max }\right)$ constrained the predicted power sold to the DSO in each MG:

$$
P_{S, D, \min } \leq P_{S, D}(i, t+k) \leq P_{S, D, \max }
$$

Also the predicted power bought from the DSO is also constrained by an upper and lower bound $\left(P_{B, D, m i n}\right.$, $\left.P_{B, D, \max }\right)$

$$
P_{B, D, \min } \leq P_{B, D}(i, t+k) \leq P_{B, D, \max }
$$

An upper and a lower bound $\left(x_{i, \min }, x_{i, \max }\right)$ constrained the stored energy in each ESS. In the i-th MG:

$$
x_{i, \min } \leq x(i, t+k) \leq x_{i, \max }
$$

The charging power must be lower than certain limited power value $P_{\text {charmax }, i}$ :

$$
0 \leq P_{\text {char }}(i, t+k) \leq P_{\text {charmax }, i}
$$

Also the discharging power must be lower than certain limited power value $P_{\text {dismax }, i}$ :

$$
0 \leq P_{\text {dis }}(i, t+k) \leq P_{\text {dismax }, i}
$$

The power sold by the $\mathrm{i}$-th MG is equal the power bought by the j-th MG:

$$
P_{B, M}(i, j, t+k)=P_{S, M}(j, i, t+k)
$$

\section{Simulation Results}

The above described optimization problem has been implemented in Matlab. We have used a modified version of the study case presented in [8]. The simulation will take in consideration five interconnected MGs. When the supply in a MG is less the demand, the solution is to discharge the ESS or purchase power from DSO or many neighbors MG. Each MG generates power and feeds a group of consumer in an interval time $(t, t+1)$. Also, it is connected to all neighboring MGs.

As for the tarif vector of selling and buying energy, $\left(T_{B, M}, T_{S, M}, T_{S, D}, T_{B, D}\right)$ are represented for each $\mathrm{MG}$ in a random value between $0.07 € / \mathrm{kWh}$ and $0.2 € / \mathrm{kWh}$ at day time, and $0.075 € / \mathrm{kWh}$ from midnight to $6 \mathrm{am}$ (Fig. 3). In Fig. 4, we show the predicted value of $P_{b a l}$ for each MG. The value is calculated based on the load and production curves of [8] where we made some random calculation to create more MGs.

The ESS can go from $25 \%$ to $90 \%$ of power storage. The power of ESS in each MG is different than the other. The sold and bought power from/to DSO is limited to $200 \mathrm{kWh}$ for each MG. The optimization algorithm searches to use the surplus power available in each MG, under constraints, and to be exchanged. If the constraints are not satisfied, the DSO interferes while respecting its constraints.

The optimal results shown in Fig.5 gives us an overview about the interaction of MG1 with the other MGs. As result of selling and buying, MG1 sells $578 \mathrm{kWh}$ in total especially $235 \mathrm{kWh}$ to MG2 and $167 \mathrm{kWh}$ to MG3 and finaly to MG4 $176 \mathrm{kWh}$. In addition, MG1 buys $235 \mathrm{kWh}$ from MG2, $158 \mathrm{kWh}$ MG4, and 224kWh MG5. So in total, MG1 buys $617 \mathrm{kWh}$. Fig.6 shows us the optimal 


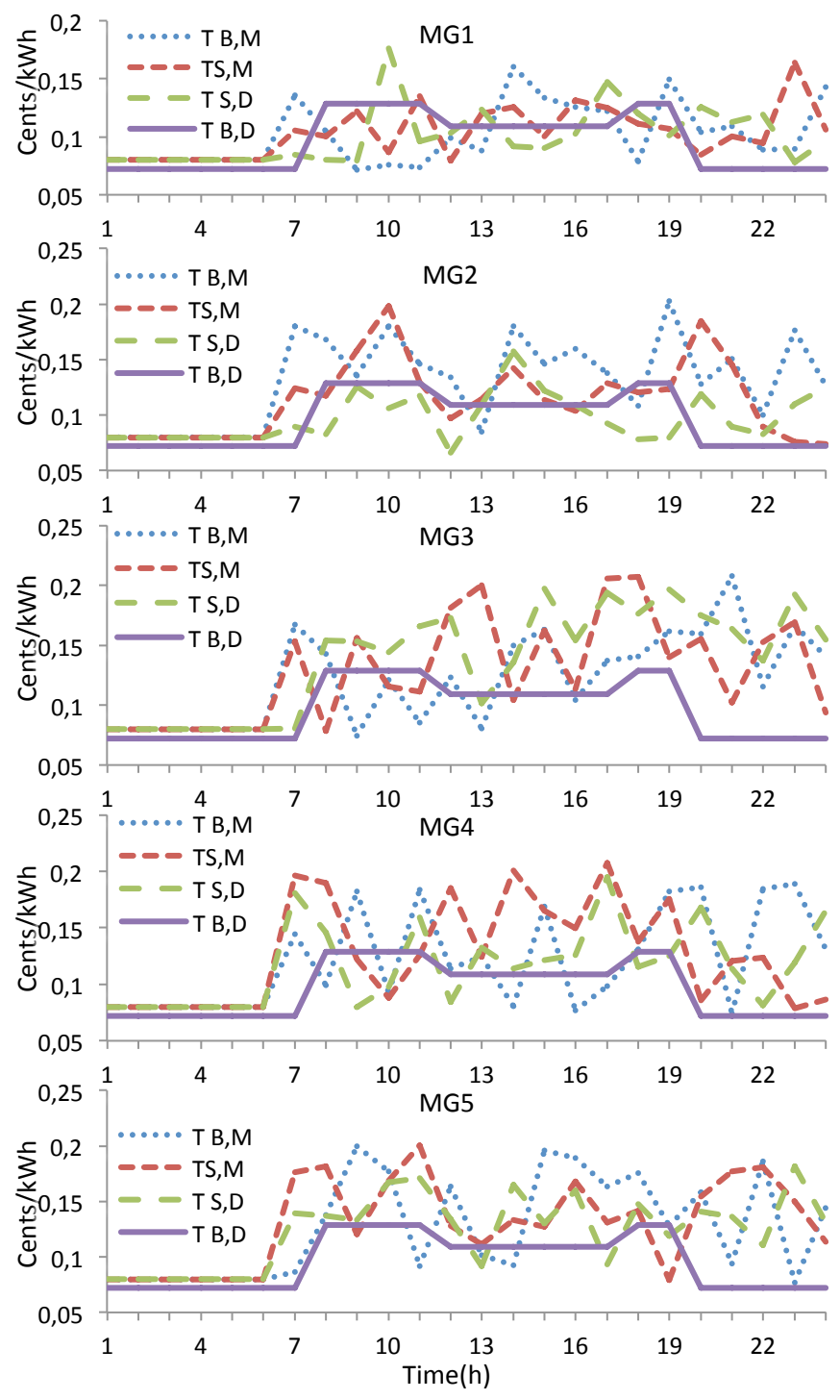

Fig. 3: The tarif vector.

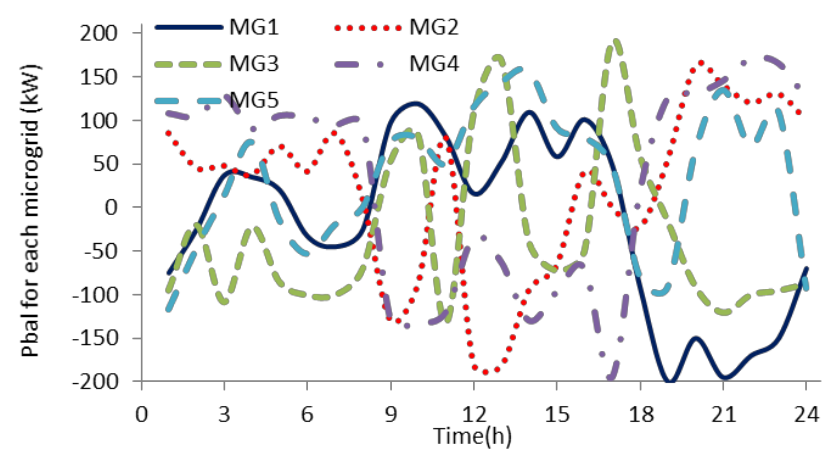

Fig. 4: MGs power balance.

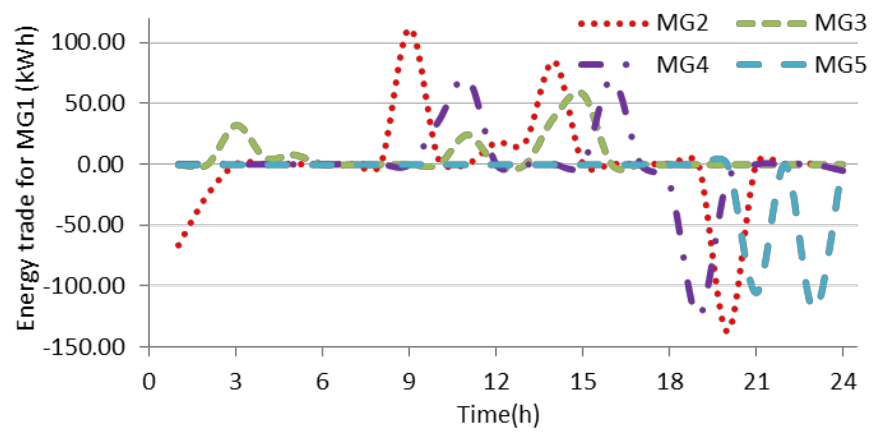

Fig. 5: Control results for MG1.

energy exchanges of MG2. The total energy bought is $871 \mathrm{kWh}$, the main bought energy is from MG3 with $526 \mathrm{kWh}$, the rest of bought energy comes from MG1 and MG5 with $235 \mathrm{kWh}$ and $110 \mathrm{kWh}$ respectively. Optimal

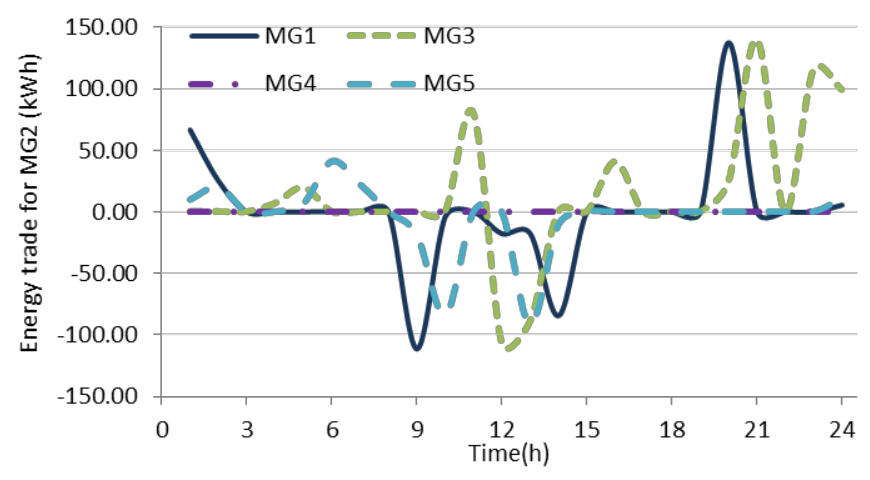

Fig. 6: Control results for MG2.

energy strategy for MG3 is shown Fig.7. It is obvious that MG3 buys energy more than selling. In total, it buys $1109 \mathrm{Kwh}$ from other MGs where the big amount comes from MG2 with 526kWh, from MG1 $167 \mathrm{Kwh}, 323 \mathrm{Kwh}$ from MG4, and 93kWh from MG5. It sells a small amount of $365 \mathrm{KWh}$ in total, distributed between MG2 and MG4 with $195 \mathrm{kWh}$ and $170 \mathrm{kWh}$ respectively. For

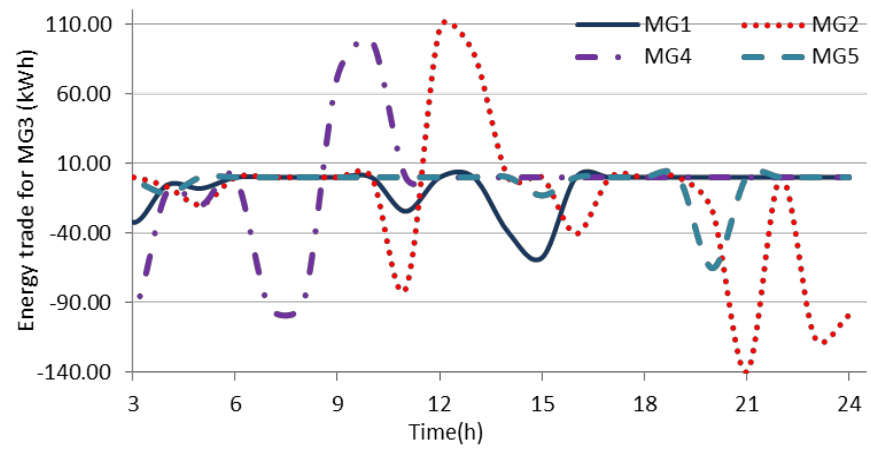

Fig. 7: Control results for MG3. 
MG4 (Fig.8), the sold energy represents $616 \mathrm{Kwh}$ where MG1 buys $158 \mathrm{Kwh}$, MG3 buys 323kWh and MG5 buys $134 \mathrm{kWh}$. Total bought energy is purchased from MG1 with 175kWh, MG2 $170 \mathrm{kWh}$ and MG5 $218 \mathrm{kWh}$. MG5

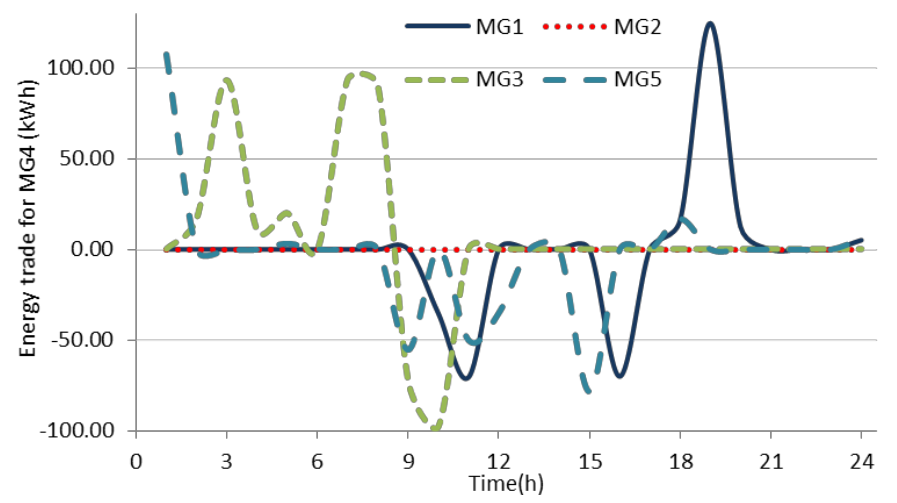

Fig. 8: Control results for MG4.

represents the maximum benefit of sold/bought energy to other MGs with a total 740/243 kWh (Fig.9). Fig.10

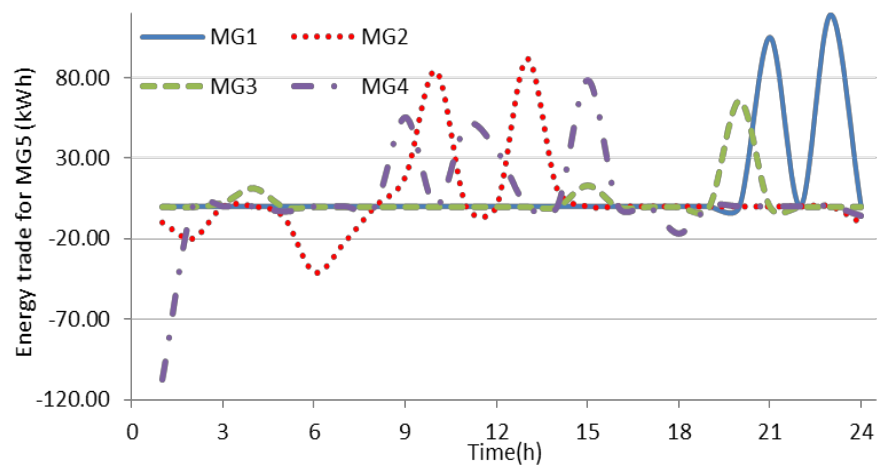

Fig. 9: Control results for MG5.

gives us the interaction between MGs and DSO in terms of power exchange. Finally, Fig.12 reveals the charge

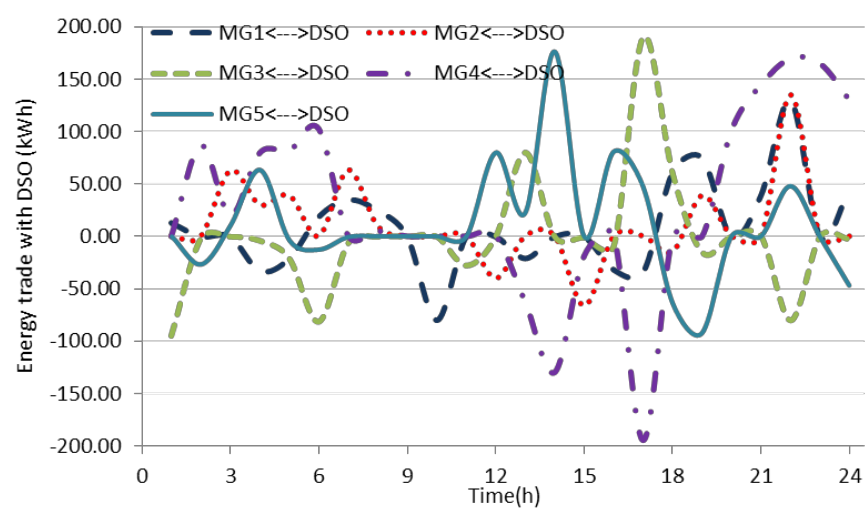

Fig. 10: Power exchange with DSO.

and discharge of ESS in each MG

\begin{tabular}{|c|c|c|c|c|c|}
\hline & MG1 & MG2 & MG3 & MG4 & MG5 \\
\hline Sell to DSO & 219 & 378 & 330 & 1088 & 529 \\
\hline Buy from DSO & 445 & 121 & 343 & 406 & 246 \\
\hline Sell to MGs & 578 & 871 & 366 & 616 & 740 \\
\hline Buy from MGs & 617 & 635 & 1109 & 565 & 244 \\
\hline
\end{tabular}

Fig. 11: Total energy exchange (kWh) between MGs and DSO.

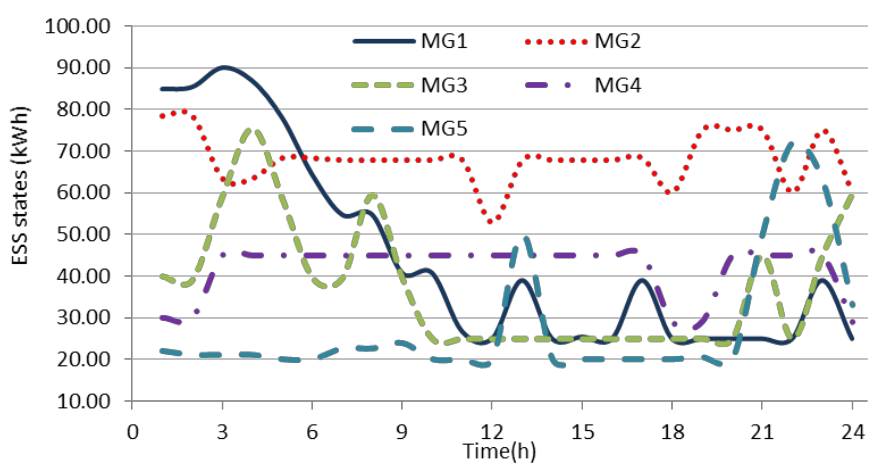

Fig. 12: Charge and discharge of ESS.

\section{CONCLUSION}

The paper presents a centralized optimization for the interaction between a network of MGs and DSO. Results has shown the performance of the proposed algorithm. Economically speaking, both MGs and DSO have gained by applying this algorithm. A decentralized version of this algorithm is under study.

\section{ACKNOWLEDGEMENT}

This work has been a joint collaboration by the project PARADISE which is sponsored by the National Research Agency (ANR).

\section{REFERENCES}

[1] H. Al-Nasseri, M. Redfern, and R. O'Gorman, "Protecting micro-grid systems containing solid-state converter generation," in Future Power Systems, 2005 International Conference on. IEEE, 2005, pp. 5-pp.

[2] J. Shah, B. F. Wollenberg, and N. Mohan, "Decentralized power flow control for a smart micro-grid," in Power and Energy Society General Meeting, 2011 IEEE. IEEE, 2011, pp. 1-6.

[3] B. Hartono, Y. Budiyanto, and R. Setiabudy, "Review of microgrid technology," in QiR (Quality in Research), 2013 International Conference on. IEEE, 2013, pp. 127-132.

[4] S. Xie, L. Xie, Y. Wang, and G. Guo, "Decentralised control of multimachine power systems with guaranteed performance," in Control Theory and Applications, IEE Proceedings-, vol. 147, no. 3. IET, 2000, pp. 355-365. 
[5] A. N. Venkat, I. A. Hiskens, J. B. Rawlings, and S. J. Wright, "Distributed mpc strategies with application to power system automatic generation control," Control Systems Technology, IEEE Transactions on, vol. 16, no. 6, pp. 1192-1206, 2008.

[6] K. De Brabandere, B. Bolsens, J. Van den Keybus, A. Woyte, J. Driesen, and R. Belmans, "A voltage and frequency droop control method for parallel inverters," Power Electronics, IEEE Transactions on, vol. 22, no. 4, pp. 1107-1115, 2007.

[7] A. Parisio, E. Rikos, and L. Glielmo, "A model predictive control approach to microgrid operation optimization," Control Systems Technology, IEEE Transactions on, vol. 22, no. 5, pp. 1813-1827, 2014.

[8] A. G. Tsikalakis and N. D. Hatziargyriou, "Centralized control for optimizing microgrids operation," in Power and Energy Society General Meeting, 2011 IEEE. IEEE, 2011, pp. 1-8.

[9] L. D. Ahmed Ouammi, Hanane Dagdougui and R. Sacile, "Coordinated model predictive-based power flows control in a cooperative network of smart microgrids," in IEEE TRANSACTIONS ON SMART GRID. IEEE, 2014, pp. 1-12.

[10] A. J. del Real, A. Arce, and C. Bordons, "An integrated framework for distributed model predictive control of large-scale power networks," Industrial Informatics, IEEE Transactions on, vol. 10, no. 1, pp. 197-209, 2014.

[11] K. Hajar, A. Hably, A. Elrafhi, Z. Obeid, and S. Bacha, "Optimization of a microgrid with renewable energy and distributed generation: A case study," in System Theory, Control and Computing (ICSTCC), 2015 19th International Conference on. IEEE, 2015, pp. 662-665. 